\title{
The Problems and Countermeasures of Patent Management in Hospital
}

\author{
Jin-guo WANG ${ }^{1, a}$ and Na WANG ${ }^{2, b}{ }^{*}$ \\ ${ }^{1}$ Department of Urology, the First Hospital of Jilin University, China \\ ${ }^{2}$ Department of Anesthesiology, the First Hospital of Jilin University, China \\ awangjinguolily@163.com, bwangna080613@163.com \\ ${ }^{*}$ Corresponding author
}

Keywords: Patent, Intellectual property, Protection, Hospital management, Productivity.

\begin{abstract}
Analyze the current situation and existing problems of hospital patent management, put forward countermeasures to improve the management of hospital patent, and then enhance competitiveness of hospital intellectual property. On the base of licensed patent statistics combined with the inventors' degrees, professional titles and their majors, we conduct a comprehensive analysis. The result shows patents are mainly in the clinical field, but patents rarely are applied into clinical practice and transferred into realistic productivity. The countermeasures include popularization of the basic patent knowledge, strengthening the patent management and promoting tracking management of patent implementation.
\end{abstract}

\section{Introduction}

It is not conducive to competition in the market. In recent years, the pharmaceutical companies are increasing spending on research and development of traditional Chinese medicine, improve the protection of traditional Chinese medicine, promote the competitiveness of the enterprise market. Therefore, traditional Chinese medicine patent applications to ascend. As such, it is suggested that scientific research institutes, colleges and universities and industrial and mining enterprises of traditional Chinese medicine research and development input, enhance the consciousness of intellectual property protection of traditional Chinese medicine, promote the traditional Chinese medicine scientific achievements into productivity, to accelerate the process of internationalization of Chinese medicine [1].

It can promote invention patent, the invention can promote the tremendous progress in medicine. In a market economy environment, the hospital is facing fierce competition, competition, the key depends on the core competitiveness patent is the core competitiveness of a powerful symbol. So hospitals in our country the status of the patent by this article, based on the comparative analysis of domestic hospital industry patents, the advantages and disadvantages in trying to predict the future the trend of the development of the hospital industry patent.

\section{The Importance of Patent in the Hospital}

\section{Patent Embodies the Innovation Ability of the Hospital.}

The era of knowledge economy competition is the competition with independent intellectual property rights the patent is the best embodiment of independent intellectual 
property rights. Market economy and economic globalization is more and more competitive. Hospital in such environment, competition is inevitable. Core competence is the key to win the competition, is the base of the long-term stability of competitive advantage. Hospital is a knowledge-intensive, economic strength and competitiveness of a hospital, the knowledge depends fundamentally on hospital have capital stock. Patent is an important indicator of intellectual capital, and embodies the core competitiveness of an important aspect [2]. Only to declare the patent, research results will get legal protection, can enjoy monopoly profits, you can create more wealth.

\section{The Current Status of Patent Management in the Hospital}

\section{Lack of Strict Careful Scrutiny}

Despite the patent management in the professional sector, but for various reasons. For the management of the patent application, maintenance, to give up more extensive, for example, in the process of scientific research personnel to patent administrative department of the hospital examination and approval system has not been established.

Be more necessary for the application materials at the end of the analysis, the pay cost accounted for only responsible for patent work, therefore, a low quality of the status of the application, repeat the application is inevitable.

\section{Focus on Papers, But Ignore Patent and Achievements}

$\mathrm{Mu}$ first, as a result of scientific research management mode which is formed by the long and the scientific research personnel through existing achievements, the patent. Intangible concept of germanium by accident, combined with the national ranking criteria for a hospital and the set of incentives are still too pay attention to the rewards of paper, so the researchers pay more attention to project declaration, published papers, achievements of academic value, the influence of the academic session, etc., as to research the market prospects, can transform and implementation are less concerned about [3]. Second, the scientific research personnel prior to application for patent, the lack of scientific and reasonable technical evaluation and market demand survey, most application purpose of topics, only pay attention to the rationality of the invention in theory and technical advancement, research results often stay in the laboratory validation phase, as to whether the results have applied value to consider.

\section{Misunderstanding of Social Meaning of the Patent System}

Part of scientific research personnel to apply for patents, as a kind of honor and promotion title, number of li will some basic research results is not stable, the market uncertainty, or did not declare the patent development value of the academic achievements, the result is often because of inadequate invention publicly or cannot reply review opinions within a prescribed period of time is regarded as an application for a patent for withdrawal [4]. Or obtained patent authorization certificate can only be on the shelf.

\section{Ignoring Patent Attachment to Application}

Published papers is proportional to the patent situation cannot, tip while ignoring patent hospital attaches great importance to the paper. Hospital attaches great importance to the dissertation mainly associated with the orientation of our country at present, such as paper sort the published annually, promotions, awards are based on paper, etc. Ignore the patent, mainly at present, the development of the hospital and the competition is not 
depends on the amount of with independent intellectual property rights, by comprehensive strength. Moreover, the number of hospital patent is less, can't compare with paper. But, we cannot ignore the patent of creativity our hospital developed a patented new drug transfer income of more than ten thousand yuan. The hospital paper number and the ratio of the number of patents significantly are below the national average.

\section{The Current Hospital Patents are Major Associated with Equipment and Materials}

Invention is very extensive in the field of medicine and health care, such as medical apparatus and instruments, hygiene materials, the configuration of the process and method, raw products drugs production methods and drugs and other products packaging and so on. Patented technology of hospital, according to most equipment and materials, followed by the method, the least is western medicine. Suggest hospital equipment and material is easier, quite a long time in the future in this aspect also is the mainstream [5]. In such aspects as methods, new USES for traditional Chinese medicine and drugs and space, we should pay attention to the researchers.

\section{Lack of Combination of the Patent Management and Scientific Research Management}

For a long time, most of the work is generally believed that the patent is only a small part of the achievements management, is not the focus of scientific research management, generally by the administrative department of the management of scientific bureau's achievements. The department is mainly responsible for the win, promotion, etc., not too concerned about in the early period of the project management, and thus the execution process patent management of scientific research project is basically a blank, resulting in the loss of part of the patent results.

\section{Suggestions}

\section{Establish and Perfect An Application System for Patents}

Push forward the project before the patent document retrieval work. Fully understand and analyze the invention into the domestic and international relevant under the premise of the latest developments in the field of technology and patent novelty search job prospects and market feasibility analysis [6]. Patent management department jointly with the related domain experts according to the characteristics of technology and value to evaluate the market prospect of the application, decide whether to apply for patent. Through a series of review, reduced the low and repeated applications, improve the quality of patents.

\section{The Exploitation of the Patent Classification Management}

Specification of technical contract text and approval process, has clear and intellectual property rights, the patent real according to project the inspection management, contract fulfillment situation promptly coordinate to deal with problems arising from the performance of the contract, ensure the smooth implementation of this project.

The center has completed and the patent agent firm, law firms, intellectual property appraisal firm, science and technology novelty search center and other intermediary contact, investigation and selection work, and set up a stable and qualified intermediary 
agency and long-term relations of cooperation, for the sustainable development of our patent work provide a good environment [7].

\section{Summary}

Hospital patent application and grant the fast growth in recent years, especially innovative strength greatly increased the number of invention patent applications received, also found that in the case of capital investment CO., LTD., increasingly heavy cost of patent management, aiming at this phenomenon, the categorized management of patents, pooling resources funded with independent intellectual property rights of science and technology innovation and application value of patent technology, improve the performance of management, patent of technology value and makes little sense to market, hospital funding only the first three years of the patent annual fee, after more than the annual fee paid by the team from the project budget. Medical institutions should try to establish a technology trading network, timely pass information of scientific and technological achievements to food industry create conditions for the technology transfer. Grope for patent achievements transformation and the cooperation pattern, the best way to accelerate the process of intangible assets to tangible assets, make the patent results quickly into a new productivity, for national economy and the development of medical service.

\section{References}

[1] Kathryn Shaw. "The Human Resources Revolution:Is it a Productivity Driver?" 2003

[2] Yager RR. On ordered weight averagi ng aggregation operators in multicriteria decisionmaking. IEEE Transactions on Systems Man and Cybernetics. 1988

[3] Torra V. the weight OWA operator. International Journal of intelligent Sys 'terns. 1997

[4] Marcy E. Rosenbaum etl. Using a Peer Evaluation System to Assess Faculty Performance and Competence. Fam.Med. 2005

[5] Judy Capko. 5 steps to a performance Evaluation system. <Family Practice Management. 2003

[6] Howard M, Weiss. Deconstructing job satisfaction: Separating evaluations, beliefs and affective experiences. Human Resource Management. 2002

[7] Dimitar Filev. On the issue of obtaining OWA operator weights. Fuzzy Sets and Systems. 1998 